http://jmscr.igmpublication.org/home/ ISSN (e)-2347-176x ISSN (p) 2455-0450 crossref DOI: https://dx.doi.org/10.18535/jmscr/v8i1.42

\title{
Management Outcome of non Traumatic Small Intestinal Perforation: A Prospective Study
}

\author{
Authors \\ Prof. (Dr) B.M. Mishra ${ }^{1}$, Dr S. Sethy ${ }^{*}$, Dr B.K. Rath ${ }^{3}$ \\ ${ }^{1}$ Prof. and HOD, Dept. of Surgery, VSSIMSAR, Burla, Odisha \\ ${ }^{2}$ Asst Prof., Dept. of Surgery, VSSIMSAR, Burla, Odisha \\ ${ }^{3} 3^{\text {rd }}$ yr PG, Dept. of Surgery, VSSIMSAR, Burla, Odisha \\ *Corresponding Author \\ Dr S. Sethy \\ Asst Prof., Dept. of Surgery, VSSIMSAR, Burla, Odisha, India
}

\begin{abstract}
Background: Small intestinal perforation peritonitis is a surgical emergency which remained a challenge to the surgeons since time immemorial. Independent of its aetiology all the cases of small intestinal perforation have similar clinical features leading to peritonitis with fulminating secondary bacterial infection for which the condition is studied as one entity.

Material and Methods: A prospective study of 40 patients presenting to VSSIMAR, Burla with a diagnosis of Small bowel perforation between November 2017 and October 2019 was done. The history, clinical features, the investigations done, the surgical procedure performed, the post-operative ICU care, the complications, the secondary procedures undertaken and mortality rate were recorded.

Results: The maximum number of cases were in the age group of 21-30yrs (32.5\%) followed by 31 40yrs (25\%) with a male to female ratio 7:3. Pain abdomen was the most common symptom. Majority of patients (42.5\%) were presented between 24-48 hrs. The most common abdominal findings were guarding / rigidity, abdominal distension each 95\%, Free gas under diaphragm found in $90 \%$ of cases. Widal test was positive in $35 \%$ cases. 8 cases (20\%) didn't respond to fluid therapy alone and required vasopressors. $85 \%$ were ileal perforation, $15 \%$ were jejunal perforation. Simple closure with drainage was the most performed procedure (65\% of cases). Typhoid \& non specific inflammation tops the aetiology (35\% each) followed by Tuberculosis (22.5\%). The most common complication was wound infection in 14 cases (35\%). Seven patients who required critical care and later on also secondary procedure were stayed longest with mean 26.28 days and range 19-36 days. The overall mortality rate was 10\%. Elderly ( $p$ $<0.001$ ), delayed presentation ( $p$ 0.001) and need of preoperative vassopressor $(p<0.001)$ were associated with high mortality.
\end{abstract}

Conclusions: Combined resuscitation and surgical management are the key for better out come. Age $>50 y$, delay in initiation of treatment and pre-op shock requiring vasopressor support are associated with high mortality.

Keywords: Non traumatic; Small intestine; Perforation; Management; Mortality; Morbidity.

\section{Introduction}

Small intestinal perforation peritonitis from a wide variety of causes comprises the majority of emergency surgical admissions in tropical countries; also has remained a challenge to the surgeons since time immemorial. Several 
aetiologies have been recorded from different geographical zones of the world. Typhoid, Tuberculosis, Amoebiasis and round worms constitute the most frequent causes, And Crohn's disease, diverticulum, volvulus and malignancy are encountered as rare causes of non traumatic small gut perforation in third world countries ${ }^{1,2}$. Independent of its aetiology all the cases of small intestinal perforation have similar clinical features leading to peritonitis with fulminating secondary bacterial infection for which the condition is studied as one entity. For the diagnosis of this condition many investigations have been formulated like straight X-ray abdomen, peritoneal tapping, haematological investigations, culture and sensitivity, widal test etc, even CT scan . But laparotomy is the ultimate diagnostic tool which gives the aetiological diagnoses with biopsy, definite site of perforation and the final treatment clue .Taking all these factors into consideration, the present work was taken up for study in department of General Surgery, Veer Surendra Sai Institute of Medical Sciences And Research (VSSIMSAR), Burla, Odisha from November 2017 to October 2019.

\section{Aims and Objective}

\section{General Objective}

- To study the management outcome of nontraumatic small Intestinal perforation.

\section{Specific Objective}

- To study the aetiology, symptoms \& signs, surgical procedures performed, and complications associated with non traumatic small intestinal perforation.

- To study the mortality rate \& probable cause of mortality associated with non traumatic small intestinal perforation.

\section{Secondary Objective}

- To study about the post op ICU care and secondary procedures performed in case of non traumatic small intestinal perforation.

\section{Material and Methods}

This observational prospective study was carried out at department of General surgery, Veer Surendra Sai Institute of Medical Sciences And Research (VIMSAR), Burla from Nov 2017 to Oct 2019 by purposive sampling.

Inclusion Criteria: Age $>12$ yrs

$\mathrm{C} / \mathrm{F}$ consistent with non-traumatic small intestine perforation

Exclusion Criteria: Age < 12 yrs

Traumatic small intestine perforation

Duodenal perforation

Cases managed conservatively

\section{Results}

Chart No-1: Age \& Sex Distribution

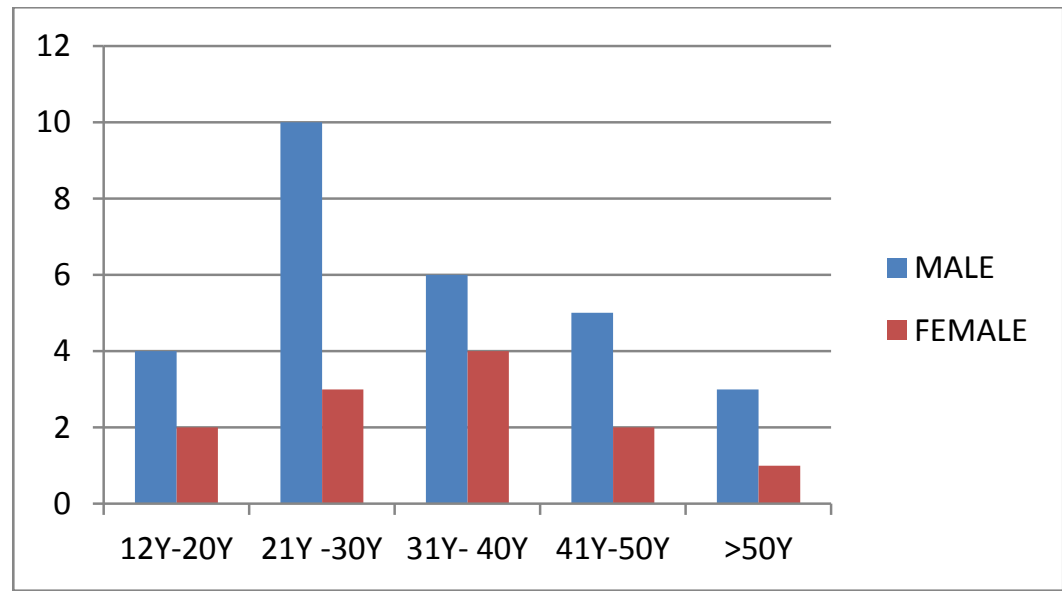


Table No 1: Symptoms and Signs

\begin{tabular}{|l|c|c|c|c|c|}
\hline PRESENTING SYMPTOMS & CASES & $\%$ & ABDOMINAL SIGNS & CASES & $\%$ \\
\hline Pain Abdomen & 40 & 100 & Guarding \& Rigidity & 38 & 95.0 \\
\hline Abdominal Distention & 36 & 90.0 & Distention & 38 & 95.0 \\
\hline Vomiting & 31 & 77.5 & Rebound Tenderness & 36 & 90.0 \\
\hline Constipation & 22 & 55.0 & Obliteration Of Liver Dullness & 36 & 90.0 \\
\hline Fever & 19 & 47.5 & Absent Bowel Sound & 36 & 90.0 \\
\hline Loose Motion & 4 & 10.0 & Ascites & 30 & 75.0 \\
\hline & & & Rectal Tenderness & 4 & 10.0 \\
\hline
\end{tabular}

Chart No 2: Duration of Delay from Appearance of $1^{\text {st }}$ Symptom to Admission in Hrs

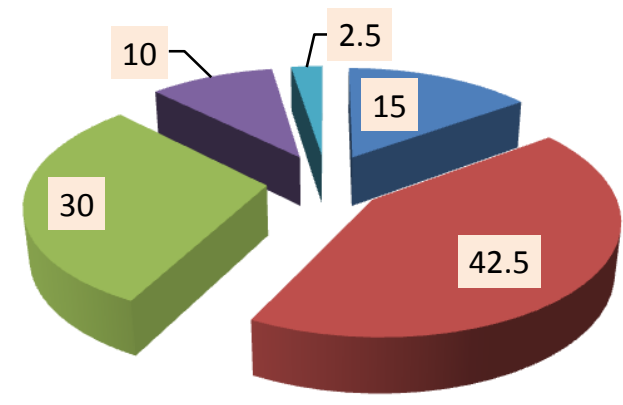

- Less than $24 \square 24-48 \square 48-72 \square 72-96 \square$ More than 96

Table No. 2: Primary Surgical Procedure

\begin{tabular}{|l|c|c|}
\hline PROCEDURE & CASES & $\%$ \\
\hline SIMPLE CLOSURE WITH DRAINAGE & 26 & 65.0 \\
\hline RESECTION \& ANASTOMOSIS WITH BYPASS AND DRAINAGE & 10 & 25.0 \\
\hline RESECTION \& ANASTOMOSIS AND DRAINAGE WITHOUT BYPASS & 3 & 7.5 \\
\hline RESECTION \& END ILEOSTOMY WITH DRAINAGE & 1 & 2.5 \\
\hline
\end{tabular}

Table No. 3: Postoperative ICU Care

\begin{tabular}{|l|c|c|c|}
\hline & & CASES & $\%$ \\
\hline \multirow{2}{*}{ ICU ADMISSION $(\mathrm{n}=40)$} & YES & 11 & 27.5 \\
\cline { 2 - 4 } & NO & 29 & 72.5 \\
\hline \multirow{2}{*}{ MECHANICAL VENTILATION (n=11) } & YES & 9 & 81.8 \\
\cline { 2 - 4 } & NO & 2 & 18.2 \\
\hline \multirow{2}{*}{ VASOPRESSORS (n=11) } & YES & 10 & 90.9 \\
\cline { 2 - 4 } & NO & 1 & 9.1 \\
\hline \multirow{2}{*}{ OUTCOME (n=11) } & SURVIVED & 7 & 76.0 \\
\cline { 2 - 4 } & DEAD & 4 & 24.0 \\
\hline \multirow{2}{*}{ DURATION OF ICU STAY IN DAYS } & \multicolumn{2}{|c|}{ MEAN- 6.72days } & $\begin{array}{c}\text { RANGE- } \\
\text { 2-11days }\end{array}$ \\
\hline
\end{tabular}

Table No 4: Histopathology of Perforation Margins and Lymph Nodes

\begin{tabular}{|l|c|c|}
\hline HISTOPATHOLOGY & CASES & $\%$ \\
\hline Typhoid & 14 & 35.0 \\
\hline Tuberculosis & 9 & 22.5 \\
\hline Jejunal Diverticulosis With Necrosis & 2 & 5.0 \\
\hline Meckel's Diverticulum & 1 & 2.5 \\
\hline Nonspecific Inflammation & 14 & 35.0 \\
\hline
\end{tabular}


Table No. 5: Post Operative Complications and secondary procedures performed

\begin{tabular}{|l|c|c|c|}
\hline COMPLICTIONS & $\begin{array}{c}\text { SECONDARY } \\
\text { PROCEDURE }\end{array}$ & CASES & $\%$ \\
\hline Wound Infection & Dressing \& Sec. Suturing & 14 & 35.0 \\
\hline Burst Abdomen* & En-Mass Closure & 2 & 5.0 \\
\hline Anastomotic Leak & $\begin{array}{c}\text { Re-Exploration \& } \\
\text { Ileostomy }\end{array}$ & 1 & 2.5 \\
\hline Enterocutaneous Fistula & $\begin{array}{c}\text { Re-Exploration+ Resection } \\
\text { \& Anastomosis }\end{array}$ & 2 & 5.0 \\
\hline ARDS & - & 2 & 5.0 \\
\hline Mortality & - & 4 & 10.0 \\
\hline No Complication & - & 17 & 42.5 \\
\hline
\end{tabular}

$* 2$ cases of burst abdomen were part of wound infection, but mentioned separately due to their severity.

All the ileostomy who were fit for surgery after 6 weeks ( 9 cases), had undergone closure.

Table No. 6: Duration of Hospital Stay

\begin{tabular}{|l|c|c|c|}
\hline PATIENT TYPE & CASES & MEAN in days & $\begin{array}{c}\text { RANGE in } \\
\text { days }\end{array}$ \\
\hline Pts neither required ICU nor 2 ${ }^{\text {nd }}$ procedure & 17 & 7.53 & $7-11$ \\
\hline Pts required ICU but $2^{\text {nd }}$ procedure not done* & 4 & 2.75 & $2-5$ \\
\hline Pts required ICU and 2 ${ }^{\text {nd }}$ procedure both & 7 & 26.28 & $19-36$ \\
\hline Pts not required ICU but $2^{\text {nd }}$ procedure was done & 12 & 15.83 & $11-26$ \\
\hline
\end{tabular}

*patients succumbed during ICU care

Table No. 7: Mortality rates in different variables

\begin{tabular}{|c|c|c|c|c|c|}
\hline VARIABLES & & DEATH & TOTAL & $\%$ & P Value \\
\hline \multirow{2}{*}{ SEX } & Male & 2 & 28 & 7.14 & \multirow{2}{*}{0.818} \\
\hline & Female & 2 & 12 & 16.67 & \\
\hline \multirow{5}{*}{ AGE } & $12-20$ & 0 & 6 & 0 & \multirow{5}{*}{$<0.001$} \\
\hline & $21-30$ & 0 & 13 & 0 & \\
\hline & $31-40$ & 0 & 10 & 0 & \\
\hline & $41-50$ & 1 & 7 & 14.28 & \\
\hline & $>50$ & 3 & 4 & 75.0 & \\
\hline \multirow{5}{*}{$\begin{array}{l}\text { DUARATION } \\
\text { OF DELAY }\end{array}$} & $<24$ & 0 & 6 & 0 & \multirow{5}{*}{0.001} \\
\hline & $24-48$ & 0 & 17 & 0 & \\
\hline & $48-72$ & 1 & 12 & 16.67 & \\
\hline & $72-96$ & 2 & 4 & 50.0 & \\
\hline & $>96$ & 1 & 1 & 100 & \\
\hline \multirow{2}{*}{ HEMOGLOBIN } & $<8$ & 2 & 10 & 20.0 & \multirow{2}{*}{0.224} \\
\hline & $>8$ & 2 & 30 & 6.67 & \\
\hline \multirow{2}{*}{ PRE-OP VASOPRESSOR } & Yes & 4 & 8 & 50.0 & \multirow{2}{*}{$<0.001$} \\
\hline & No & 0 & 32 & 0 & \\
\hline \multirow{2}{*}{$\begin{array}{l}\text { SITE OF } \\
\text { PERFORATION }\end{array}$} & Ileum & 4 & 34 & 11.76 & \multirow{2}{*}{0.376} \\
\hline & Jejunum & 0 & 6 & 0 & \\
\hline \multirow{5}{*}{ PATHOLOGY } & Typhoid & 1 & 14 & 7.14 & \multirow{5}{*}{0.113} \\
\hline & Tuberculosis & 2 & 9 & 22.22 & \\
\hline & Non Specific & 1 & 14 & 7.14 & \\
\hline & Jejunal Diverticulosis & 0 & 2 & 0 & \\
\hline & Meckel's Diverticulosis & 0 & 1 & 0 & \\
\hline \multirow{4}{*}{ PROCEDURE } & Simple Closure & 1 & 26 & 3.85 & \multirow{4}{*}{0.069} \\
\hline & R \& A With Bypass & 3 & 10 & 30.0 & \\
\hline & R \& A Without Bypass & 0 & 3 & 0 & \\
\hline & R \& End Ileostomy & 0 & 1 & 0 & \\
\hline
\end{tabular}




\section{Discussion}

This study was carried out at VSSIMSAR, Burla from Nov 2017 to Oct 2019. 467 cases of acute abdomen were admitted during this period out of which 180 cases were due to perforations of various part of gastrointestinal tract. Out of these 180 cases of various perforations small intestinal perforations were screened out and it was found in 40 cases $(22.22 \%)$ and out of total acute abdomen case it was $8.5 \%$. Because of high propensity, the Surgeon should bear in mind the possibility of non traumatic small intestinal perforation while examining a case of acute abdomen.

In this series we observed $47.5 \%$ of the cases in young adults 12 to 30 years of age and maximum cases were in $2^{\text {nd }}$ decade $(32.5 \%)$ followed by $3^{\text {rd }}$ decade $(25 \%)$. The male to female ratio was 7:3. Nair et $\mathrm{al}^{\mathbf{3}}$ (1981) in their observation have observed that male suffer 3-4 times more frequently then female and most of the patients were in 2 and 3 decade of life.

The common presenting symptoms of our series were pain abdomen $(100 \%)$, abdominal distension (90\%) and vomiting (77.5\%) . $80 \%$ of patients had tachycardia, $70 \%$ of patients had shock at the time of presentation . Guarding and rigidity, abdominal distension found in all cases ; rebound tenderness, obliterated liver dullness and absent bowel sound were present in $90 \%$ of cases. Free peritoneal fluid was seen in $75 \%$ cases and per rectal tenderness observed in $10 \%$ cases The low incidence of fever $(45 \%)$ as compared Nair et $\mathrm{al}^{3}$ (100\%)may be attributed to prior treatment and different etiologies . Dickson and Cole ${ }^{1}$ observed diarrhoea in $42 \%$ of their series. The low incidence of diarrhoea $(10 \%)$ is because of the absence of amoebiasis in this series.

Leucocytosis in $50 \%$ of cases and leucopenia in $15 \%$ (may be due to Enteric fever) were observed. Severe anaemia found in $25 \%$ cases. All patients were subjected for ' $\mathrm{X}$ ' ray abdomen in erect posture and $90 \%$ of cases had free gas under the dome of diaphragm and $50 \%$ had distended coils of intestine with multiple fluid levels. Serum creatinine was raised in 34 cases, out of which 8 cases had values above $3 \mathrm{mg} / \mathrm{dl}$. Hyponatremia found in $92.5 \%$ of cases, where as hypernatremia found in $2.5 \%$ cases. Hypokalemia found in $60 \%$ of cases \& hyperkalemia was seen in $5 \%$ of cases. Widal test was positive in 14 cases.

All the cases were subjected to preoperative resucitation. Nasogastric aspiration, intravenous fluids, and antibiotics were routinely given to all patient and blood transfusion (25\%), vasopressors $(22.5 \%)$ and oxygen (10\%) were given where ever required. Ahmed et $\mathrm{al}^{4}$ (1962) had the opinion to resuscitate all cases pre-operatively and then to proceed for the laparotomy.

On laparotomy purulent and faeculent fluid came in all 40 cases and adjacent mesenteric lymphadenopathy in $22.5 \%$ cases . Karmakar et $\mathrm{al}^{6}$ (1972) found typhoid in 17 cases out of 30, where as we got 14 out of 40 cases. The low incidence may be due to early diagnosis of the disease by modern method of investigation and treatment by newer antibiotics. Out of 40 cases, Tuberculosis was found in 9 cases. Perforated Meckel's diverticulum was found in 1 case only, may be due to exclusion of under $12 \mathrm{yr}$ children in our study. In rest 14 cases no specific cause could be ascertained, so they were grouped under nonspecific perforation. Nandkarni et $\mathrm{al}^{7}$ (1987) attributed the perforation of small intestine to be maximum due to typhoid in tropical countries and round worm is an associated finding.

At first the site of perforation was identified and management was done according to cause, site, number of perforation; bowel condition and general condition of patients. Through peritoneal toileting was done in all cases. Simple Closure with drainage was done in 26 cases with single perforation with a healthy bowel. In 10 cases with either multiple ileal perforations or tuberculosis, resection \& anastomosis with proximal loop ileostomy was done. Three cases of diverticulosis undergone resection \& anastomosis without bypass and only one case of gangrenous ileum undergone resection \& end ileostomy as the bowel was unhealthy. In all the 40 cases bilateral flank drains were given. The drainage tube was kept for 
3- 6 days to drain the residual infected materials. In all the 40 cases, we used empirically ceftriaxone (Igm/12hrly) and metronidazole $(500 \mathrm{mg} / 8 \mathrm{hrly})$. The antibiotics later on changed according to culture \& sensitivity report. In Typhoid the ceftriaxone dose would be doubled. In case of Tuberculous perforation, in addition to above antibiotics, anti tubercular drugs according to RNTCP guideline are given on post op day 4 onwards.

In this study 11 cases out of 40 required ICU care post operatively. The indications for ICU care were lack of effort during anaesthesia recovery, persistent severe shock, acute renal failure and ARDS not responding to non invasive ventilation. Nine cases (81.8\%) required mechanical ventilation and 10 cases $(90.9 \%)$ required vasopressor support . During ICU care 4 patients succumbed to death. The cause of death was septic shock in 3 patients and acute or chronic kidney disease with progressive renal failure in one case. 7 patients survived and transferred to ward .

All possible measures for peri-operative care were rendered, in spite of that 19 cases developed complications and 4 cases died; uneventful recovery noted in 17 cases. The most common complication encountered was wound infection in 14 cases, out of these 14 cases 2 landed in burst abdomen. Two patients developed ARDS on post op period, one patient had anastomotic leak. 2 cases of enterocutaneous fistula observed. 12 cases of wound infections undergone regular dressing followed by secondary suturing. Two cases of burst abdomen were resuscitated and emergency basis en-mass closure was done. One case of anastomotic leak was identified on post op day 4; as the patient had stable hemodynamics, reexploration was done and an end ileostomy was performed. Two cases of enterocutaneous fistula and all ileostomies from primary and secondary procedures were built up nutritionally for 6 weeks at least. After that re-exploration and resection \& anastomoses was done for enterocutaneous fistula; and ileostomy closure was done for cases of ileostomy.

In our series we have noted $10 \%$ overall mortality. Mortality is high in patients with age $>50 \mathrm{yrs}$ ( $\mathrm{p}$ $<0.001)$, delayed presentation $(\mathrm{p} 0.001)$, patient requiring preoperative vassopressors $(\mathrm{p}<0.001)$. Olurin et $\mathrm{al}^{5}$ (1972) reported $31 \%$ mortality, Nadkarni et $\mathrm{al}^{7}$ (1987) have observed $12.5 \%$ mortality, Khorwal B et al $^{8}$ (2015) reported $11 \%$ mortality in their series of non-traumatic small bowel perforation. The mortality in our study is comparable to Khorwal B \& Nandakarni and much less than other studies above mentioned.

\section{Conclusion}

From our study we can conclude that non traumatic small intestinal perforation is more common in $2^{\text {nd }} \& 3^{\text {rd }}$ decade with a male preponderance and most commonly presented as pain abdomen. Erect abdomen X-ray showing both dome of diaphragm is very useful investigation. Typhoid \& non specific inflammation tops the aetiology followed by Tuberculosis. Combined resuscitation and surgical management are the key for better out come. Wound infection is the most common complication. The age $>50 \mathrm{yr}$, delay in initiation of treatment and pre-op shock requiring vasopressor support are associated with high mortality.

\section{Conflicts of interest - None}

\section{Reference}

1. Dickson JAS and Cole GJ. Perforation of the terminal ileum; A review of 38 cases, British Journal of Surgery. 1964 ;51:893-7

2. Taylor BA. Gastro intestinal emergencies: Glimore Ian T, Robert Shields. Spontaneous perforation of the gut.1st ed. WB Saunder company: 1992:359-79

3. Nair SK, Singhal VS, Sudhir K. Nontraumatic intestinal perforation.Ind J Surg 1981; 43(5):371-78. 
4. Ahmed $\mathrm{M}$ et al, Acute tubercular perforation of small intestine, Indian Journal Med Association, 1962;38:317-321

5. Olurin E O. Typhoid perforation. J Roy Col Surg. Edinberg. 1972; 17:353-63

6. Karmakar S R, Bhalerao R A. Perforation of terminal ileum. Ind J surg 1972 nov;34:422-6

7. Nandakarni K M, Shetty SD, Kagzi RS,Pinto AC , Small bowel perforation: Astudy of 32 cases ,Archives of Surg1981 Jan;116(1):53-7

8. Khorwal B,Yadav KS et al.Study of predictive ability of modified APACHE II score to prognostigate the outcome and severity of generalised peritonitis due to Typhoid ileal perforation. J Evolution Med Dent Sci 2015 Nov;4(90):15498-501. 